Article

\title{
Cosmetic Potential of a Liotropic Liquid Crystal Emulsion Containing Resveratrol
}

\author{
Laura Bonato Alves Oliveira ${ }^{1}$, Rafaela Pereira de Oliveira ${ }^{1}$, Camila Oliveira ${ }^{1}$, \\ Nádia Rezende Barbosa Raposo 2,3, Marcos Antônio Fernandes Brandão ${ }^{2}$, \\ Anderson de Oliveira Ferreira ${ }^{3}$ and Hudson Polonini ${ }^{1,3, *}$
}

1 Faculdade de Ciências Médicas e da Saúde de Juiz de Fora (SUPREMA), Juiz de Fora, MG 36036-900, Brazil; laurabonato.oliveira@hotmail.com (L.B.A.O.); rafajf2011@hotmail.com (R.P.D.O.); oliveiracmla@yahoo.com (C.O.)

2 Núcleo de Pesquisa e Inovação em Ciências da Saúde (NUPICS), Universidade Federal de Juiz de Fora (UFJF), Juiz de Fora, MG 36036-900, Brazil; nadiacritt@gmail.com (N.R.B.R.); marcosbrand2012@gmail.com (M.A.F.B.)

3 BF-Fox Technologies, Juiz de Fora, MG 36036-900, Brazil; anderson@ortofarma.com.br

* Correspondence: h.c.polonini@gmail.com; Tel.: +55-32-99117-8637

Received: 4 November 2017; Accepted: 4 December 2017; Published: 7 December 2017

\begin{abstract}
Resveratrol is a natural substance that has been the target of many researchers over the years since it presents a variety of potential applications in the areas of cosmetics and medicine as a treatment for some diseases. Due to its high antioxidant capacity but low bioavailability, we evaluated the antiaging potential of resveratrol as a liotropic liquid crystal emulsion. Initially, we performed in vitro assays to quantify both the organoleptic characteristics and stability of the emulsion. Next, an in vivo trial was performed on the faces of 30 volunteers to determine the cream's cosmetic potential and to measure porphyrins, skin barrier function, skin pigmentation, expression lines, and porosity. The emulsion maintained its characteristics during the in vitro assays and, in the in vivo trial, it had some effect only on pore size in forehead, without any significant effects on the other parameters. We had 6 dropouts throughout the study, then the final number of volunteers was 24 . Most volunteers did not show any changes in skin pigmentation throughout the study. Similarly, there was not any noticeable improvement on any other parameters evaluated. However, volunteers related a high level of satisfaction with the product.
\end{abstract}

Keywords: resveratrol; liquid crystal; antiaging; cosmetic

\section{Introduction}

Healthy skin is determined mainly by percutaneous absorption, plasticity, and cellular renovation [1]. During the aging process, there is a lack of organization of these characteristics along with the loss of its antioxidant defense capacity, which causes an imbalance in the epithelium, resulting in an increase of free radical levels [1,2]. Currently, these factors are considered the main causes of the aging process. Free radical species causes oxidative stress in biological structures, resulting in the appearance of both physiological and biochemical changes leading to phenotypic consequences such as expression lines, flaccidity, low hydration, and skin pigmentation [2,3].

In this regard, there is widespread interest in the development of cosmetics that could act to decrease effects of free radicals in the skin, as the human skin ages possibly because the cells accumulate free radical damage throughout time. However, the development of antiaging cosmetic emulsions for topical use is, in general terms, a big challenge [3]. First, the system is inherently unstable once it is made since it is composed of a blend of two insoluble liquids united by a surfactant layer [2,3]. Another important point to be considered is that for this type of formulation to have the desired effect, the substance must be 
both absorbed by the skin and released at the target tissue in its active form [2]. Such a process is related to the molecular arrangement, the physicochemical properties of the active pharmaceutical ingredients (API), and the vehicle used in the formulation. In this context, one of the molecules that has been a current target of research in the cosmetic field is resveratrol [1-4]. Resveratrol (3,4,5-trihydroxy-trans-stilbene) is a natural phenolic compound produced by some spermatophyte species in response to attacks by pathogens or exposure to ultraviolet radiation or ozone. This molecule has been studied by many researchers for having a variety of beneficial effects on health. Resveratrol acts in a preventive and healing way in many diseases because of its anti-inflammatory, antioxidant, neuroprotective, cardioprotective, antiviral, anticarcinogenic, photoprotective, antimicrobial, and antiaging effects [4-7]. The antioxidant effect of resveratrol seems to be related to the inhibition of cyclooxygenase, hydroperoxidase, kinase $\mathrm{C}$ protein, $\mathrm{Bcl}-2$ phosphorylation, kinase B protein (PKB or Akt), focal adhesion kinase, NF-kB, matrix metalloproteinase 9, and cell cycle regulators $[5,6]$. It has demonstrated great potential for use as a more efficient means to combat lipid peroxidation when compared with vitamins C and E (95\%, 65\%, and 37\%, respectively) [8]. Besides its antioxidant effect, resveratrol has been reported to be an important selective inhibitor of tyrosine kinase, a key melanogenesis catalyst enzyme, suggesting that it can also be used as a skin-lightening agent [8-11]. Recent studies have shown that this substance has an important photoprotective effect once it acts on cell signaling mechanisms related to photoaging caused by ultraviolet radiation (UVA and UVB rays) [7-10]. According to Polonini et al., when applied topically, the chemopreventive, antiproliferative, and photoprotective properties of resveratrol are emphasized [4].

Among the different cosmetics produced, emulsions are widely used to incorporate incompatible cosmetic components [1]. Despite the existence of some commercial products containing resveratrol, there are no studies on its incorporation into emulsions made with liotropic liquid crystals [4,6-8]. Liquid crystal systems are more stable when compared with other emulsions because they promote higher cutaneous hydration by retaining water in the corneal layer and delivering the sustained release of active ingredients to target areas. When the chemical structure is compared with the composition and disposition of both lipids and water present in the epidermis, an emulsion is the best option to address cutaneous issues in the cosmetic field, in particular, as an antiaging treatment [9-14].

In this context, several advantages of using the liquid crystal formulation in cosmetics include: (i) visual features, some crystals possess properties such as thermochromism (some substances change their colors at different temperatures); (ii) protective properties, substances incorporated in the liquid crystal matrix, or the formulation made with it, have protection against photo- or thermo-degradation because of its microstructure; (iii) hydrating properties, promote an increase in water retention in the stratum corneum layer resulting in a higher cutaneous hydration and an extended release of substances because its chemical structure is similar to the composition arrangement of lipids and water in the human epidermis; and (iv) stability, have a higher physicochemical stability when compared with traditional emulsions [12-14].

In this sense, a liotropic liquid crystal emulsion containing resveratrol is hypothesized to act as an effective antiaging cosmetic that could work on both molecular and cellular changes that occur in aging processes. These changes are visible mainly because of the action of free radicals that cause a decrease in cell proliferation, elasticity, and capability of realizing gas exchange. Ultimately, free radicals result in the appearance of expression lines, skin pigmentation, a decrease in skin thickness, and dry skin [15-17]. Besides these phenotypic changes, psychosocial changes may occur because high self-esteem bolsters good mental and physical health [17].

Among the many procedures that can be performed, namely laser sessions, intensely pulsed light treatments, photodynamic therapy, facial filling with hyaluronic acid, botulinum toxin injections, chemical peels, radiofrequency sessions, and dermabrasion procedures, one can also consider antiaging creams [16]. These creams are used as a home care treatment, present a lower risk when compared with other procedures, and can delay and/or improve the signs of aging skin. 
The aim of this work is to evaluate the cosmetic potential of a multipurpose liotropic liquid crystal emulsion containing resveratrol for use in human volunteers, as well as to determine some relevant physicochemical properties of the product.

\section{Materials and Methods}

\subsection{Materials}

The composition of the emulsion is stated in Table 1. Resveratrol dosing was chosen based on previous works from our group $[4,10]$, which report biological activities at $10 \%(\mathrm{w} / \mathrm{w})$, when used topically instead of orally.

Table 1. Composition of the liquid crystal-based emulsion with resveratrol.

\begin{tabular}{cccc}
\hline Ingredient & INCI Name & $\begin{array}{c}\text { Concentration } \\
(\mathbf{\%}, \mathbf{w} / \mathbf{w})\end{array}$ & Supplier \\
\hline Resveratrol & Vitis Vinifera (Grape) Leaf/Skin/Seed Extract. & 10 & Infinity Pharma (Brazil) \\
\hline Transcutol ${ }^{\circledR}$ & Diethylene Glycol Monoethyl Ether. & 7 & Fagron (Brazil) \\
\hline FagPlus ${ }^{\circledR}$ Cristal & $\begin{array}{c}\text { Propylen glycol, methylparaben, } \\
\text { phenoxyethanol, methylparaben, ethylparaben, } \\
\text { propylparaben, butylparaben, isobutylparaben * } \\
\text { imidazolidynil urea, ammonium } \\
\text { acryloyldimethyltaurate/VP copolymer, cetearyl } \\
\text { alcohol and polysorbate 60 and cetearyl } \\
\text { glucoside and stearyl alcohol, caprylic/capric } \\
\text { triglyceride, octyl steareth, water. }\end{array}$ & 83 & Fagron (Brazil) \\
\hline${ }^{*}$ isobutylparaben was banned in European cosmetics products by Commission Regulation (EU) No 358/2014.
\end{tabular}

Resveratrol was measured, and soon thereafter, it was transferred to a porcelain mortar and pestle. Transcutol ${ }^{\circledR}$ was measured in a graduated cylinder, and it was used for the resveratrol levigation, to form a paste. The FagPlus ${ }^{\circledR}$ Cristal was added to the paste and mixed for two minutes using a spatula. Later, a roll mill was used to mix the cream for seven minutes, and the final formulation was packed in a plastic tube and labeled. It is important to note that the base was used as received, and so the composition and characteristics of the liotropic liquid crystal are as stated by the supplier.

\subsection{Physicochemical Characterization}

\subsubsection{Macroscopic Characterization}

Organoleptic parameters were evaluated by the observation of the visual aspect, color, odor, and tactile sensitivity [18-20].

\subsubsection{Stability Experimentation}

\section{Centrifuge assay}

Five grams of the prepared formulation was centrifuged at $3000 \mathrm{rpm}$ at $25^{\circ} \mathrm{C}$ for $30 \mathrm{~min}$, using a Q22 TM centrifuge (Quimis). At the end of the assay, maintenance of formula homogenization verified system stability.

\section{pH Determination, viscosity, and water proportion}

An analytical balance AUW220 (Shimadzu, Rosario, Cavite, Philippines) was used to measure $500 \mathrm{mg}$ of the final formulation that was immediately sent to the Karl Fisher analyzer KF1000 (Analyser, São Paulo, SP, Brazil). As soon as the cream was compounded, the $\mathrm{pH}$ of the emulsion was measured using a digital pH meter. The Brookfield ViscoBasic Plus R (Fungilab, Barcelona, Spain) connected to a Heldal unit was used to measure viscosity at $25^{\circ} \mathrm{C}, 5 \mathrm{rpm}$, using a PE spindle from the same manufacturer. Results were expressed as the mean \pm standard deviation from three genuine replicates. 


\subsection{In Vivo Trial of Cosmetic Activity}

\subsubsection{Volunteers}

This study evaluated 30 human subjects living in Zona da Mata Mineira (Brazil). Inclusion criteria were subjects: (a) who were in good health; (b) with intact skin on the face; (c) who agreed to sign both procedures and demands of the study and return to the Institute on designated days and times for evaluations; (d) who could provide written consent to participate in the trial; (e) from both genders and any ethnic group; and (f) with age between 20 and 60 years old. Exclusion criteria were subjects who: (a) had used any anti-aging product for at least 6 months before the start of the study; (b) were using sunscreen; (c) had any declared allergic reaction to compounds of the formula used; and (d) had treatment with topical or systemic medicines for acne in the previous 30 days from the beginning of the study.

All participants were entered into the study after providing written consent. They applied the cream twice a day, for 45 consecutive days (once in the morning and another time at night; i.e., every $12 \mathrm{~h}$ ). Cosmetic parameters were evaluated biweekly, and an initial evaluation was made before starting the treatment. As this is an explanatory, self-controlled study (baseline vs. end of treatment), no negative control (e.g., resveratrol solution) was used.

\subsubsection{Pores, Skin Pigmentation, and Expression Lines}

A Visioscope PC $35^{\circledR}$ (Courage + Khazaka electronic GmbH, Köln, Germany) was used to make a visual analysis of the skin area to detect pores size, skin pigmentation, and expression lines. The right cheek and the forehead were evaluated in this study to detect pores and skin pigmentation. Expression lines were evaluated on the forehead, on the outside corner of the right eye, and on the right cheek. The Complete Skin Investigation (Courage + Khazaka electronic GmbH, Köln, Germany) software was used to establish parameters.

\subsubsection{Porphyrin}

The forehead, cheeks (left and right), the nose, and the chin areas were evaluated using Visiopor ${ }^{\circledR}$ PP 34 N (Courage + Khazaka electronic GmbH, Köln, Germany) to detect the porphyrins. The equipment camera was placed in direct contact with the skin to take an image that was analyzed by the Visiopor ${ }^{\circledR}$ PP 34 N software.

\subsubsection{Transepidermal Water Loss}

The forehead, the cheeks (left and right), the nose and the chin areas were evaluated using the VapoMeter (Delfin, Finland) to indicate the skin barrier function. The VaporMeter was put in contact with the area analyzed, and the transepidermal water loss was determined as g of water $/ \mathrm{m}^{2} / \mathrm{h}$.

\subsubsection{Questionnaire}

At the end of the study, a questionnaire with a qualitative approach was delivered to participants to evaluate their perception of the developed formulation and the way the study was conducted, elaborated, and it was. This questionnaire was composed of 12 simple and direct questions and also had free space for volunteers to express their opinions about the study.

\subsubsection{Statistical Analyses}

Statistical analyses were performed using SPSS (v. 20.0, IBM, North Castle, NY, USA). For comparisons among control (baseline parameters, $t=0$ ) and treatments, Analysis of Variance (ANOVA) followed by Tukey's post-hoc test was conducted for the variables meeting the criteria of normality (Shapiro-Wilk test, $p>0.05$ ), homoscedasticity (variance homogeneity, Levene test, $p>0.05$ ) and independence (Durbin Watson test, $p \sim 2.0$ ). For the variables which violated the assumptions for 
ANOVA validity, the non-parametric Kruskal-Wallis test was conducted. Differences between groups were considered statistically significant when $p<0.05$.

\subsection{Ethics}

The present project was conducted in accordance with the standard protocol of the Declaration of Helsinki and approved by the Ethics Committee of the Faculdade de Ciências Médicas e da Saúde de Juiz de Fora (Suprema), being approved under the advice number: 2.017.037.

\section{Results}

\subsection{In Vitro Assays}

The chosen vehicle for substance incorporation is mineral oil-free, non-comedogenic; and its main characteristic is the formation of liotropic liquid crystals that form a rigid structure, providing the formulation with a higher stability and promoting real skin hydration [17]. All following numerical results of this section are expressed as the mean \pm standard deviation from 3 separate determinations.

The proposed formula had a grayish-white tone, was homogeneous, and had a bright aspect, characteristic raw material fragrance (see Figure S1 in Supplementary Material), and pH close to neutrality $(6.33 \pm 0.02)$. At the end of the centrifuge assay, there was no phase separation, confirming emulsion stability. The value of the water determination result was $58.33 \pm 1.45 \%$ and viscosity was $23.0 \pm 1.0 \mathrm{CP}$. The product offered a cream that was light sensitive, dry touch, easily spreadable, and rapidly absorbed by the skin.

\subsection{In Vivo Trial}

This was an exploratory study and therefore no information was available on the size of any possible effect. Given this, no preliminary calculation of the sample size was made, and 30 volunteers were pre-selected. One volunteer abandoned the study before it started and five were lost during follow up. Only one volunteer was lost for a reason directly connected to the proposed cosmetic that he said was because of increased skin oiliness. However, before starting the study, he was using a treatment to control acne and oily skin (not related by him during the first phases of the study), although not presenting any visual signal of acne. The other volunteers could not finish the trial because they claimed they did not have time to go to the laboratory $(n=4)$. At the end of the study, 24 volunteers (18 women and 6 men) remained, with an average age of $37.2 \pm 14.4$ years old (standard deviation); having a minimum age of 21 and a maximum age of 55. We have presented only the results of these 24 volunteers in the next tables containing the results. As this is a small population and the treatment effect parameters evaluated are not straightforward in the presence of dropout, no significant loss on the interpretation of data occurred.

\subsubsection{Pore Size Evaluation}

Over the years, the structure of the skin is modified, and the combined action of extrinsic factors results in a decrease in the thickness of the epidermis. This epidermal thinning is due to both the decrease in and degeneration of collagen fibers and a progressive increase in the number, fragmentation, and porosity of elastic fibers in the dermis $[15,17,21,22]$.

As pores are related to skin aging, they were quantified, and the results are presented in Table 2 and Figure 1. There is no reference value for pore size as it varies among populations. The parameter used was the direct comparison within the same volunteer and within the population (using average values). Almost $79 \%$ of volunteers $(n=19)$ presented a progressive reduction in pore size on the forehead, and $58 \%(n=14)$ presented a reduction in pore size on the cheek. At the end of the study, there was a decrease of pore size only in forehead and not in the right cheek.

Interestingly, a study conducted by Flament et al. [23] with a larger sample of subjects ( $n=2585$ women) found individual pore surface on cheeks in the range of 0.06 to $0.16 \mathrm{~mm}^{2}$, which means 
on average $0.37 \mathrm{~mm}$ of diameter (i.e. $370 \mu \mathrm{m}$ ). These values were much higher than those found in our study. However, the work of Flament et al investigated subjects claiming to have large skin pores. They also used a different equipment (a Dermascore ${ }^{\circledR}$ system, a portable dermatoscope with polarized lighting), which can account for the huge discrepancy on the results, as this equipment measures the area of the pores, while the one we used measures only two-dimensional diameter of skin pores. Even so, further and deeper investigations are recommended to clarify such differences to the values report in the literature.
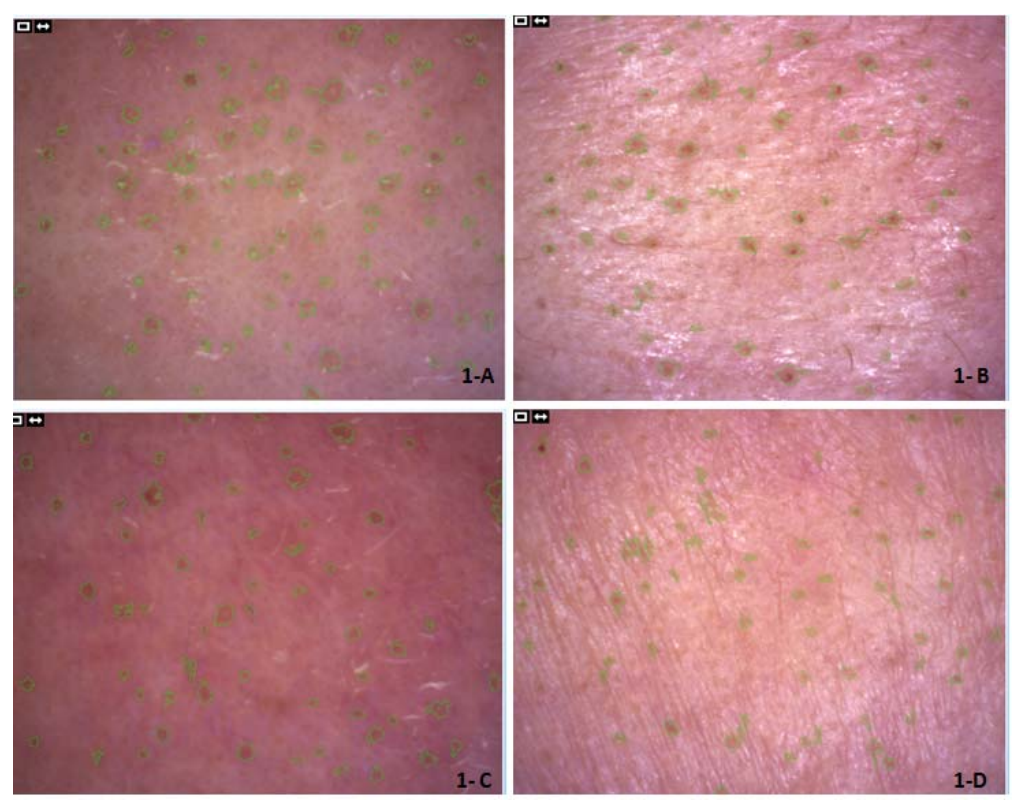

Figure 1. Graphic of typical results for the pore determination. (1-A): Forehead on days 0 and (1-B) Forehead on day 45; (1-C) Right cheek on day 0; (1-D) Right cheek on day 45. Both in volunteer 24. Pores can be visualized by the green marking.

Table 2. Average results of pore evaluation on the forehead and the right cheek of volunteers.

\begin{tabular}{ccc}
\hline \multirow{2}{*}{ Day of Measurement } & \multicolumn{2}{c}{ Pore Size $(\mu \mathrm{m}, \mathbf{n}=\mathbf{3} ; \mathbf{2 4} \text { Subjects })^{*}$} \\
\cline { 2 - 3 } & Forehead & Right Cheek \\
\hline 0 & $3.5 \pm 0.5$ & $2.4 \pm 1.0$ \\
15 & $2.9 \pm 1.3$ & $2.4 \pm 0.7$ \\
30 & $2.5 \pm 1.1$ & $2.4 \pm 0.9$ \\
45 & $2.5 \pm 0.8^{* *}$ & $2.1 \pm 0.9$
\end{tabular}

* Results expressed as the mean \pm standard deviation of 3 separate determinations from each skin site in each subject. ${ }^{* *}$ Statistically significant difference $(p<0.05)$.

\subsubsection{Evaluation of Skin Pigmentation}

Ultraviolet radiation is considered the main cause of extrinsic aging or photoaging [24]. This type of aging is a cumulative process and depends on the amount of solar exposure [25]. Skin changes caused by solar exposure are presented as yellowish skin and irregular pigmentation $[25,26]$.

At the end of the trial, 13 volunteers presented skin on their forehead, and 15 volunteers presented skin on their right cheek that had not had any skin change from the beginning to the end of the study, as shown in Table 3 and Figure 2. Approximately $29 \%$ of volunteers $(n=7)$ showed a decrease in skin pigmentation on the forehead, and only $16 \%(n=4)$ had a reduction in skin pigmentation on the right cheek. However, 4 of the 24 volunteers evaluated, presented an increase in pigmentation on the forehead region and 5 on the right cheek region. Such a result might have occurred because volunteers suspended the use of sunscreen to participate in the study thereby making them more vulnerable to 
the effects of solar radiation possibly resulting in cutaneous hyperpigmentation. The short time of the trial could also have accounted for the negligible effects. Additionally, we can observe that most volunteers did not present skin pigmentation at the beginning of the trial; they remained stable with regard to this parameter through the evaluation, but not effect could be reported in volunteers who did not need improvements in this parameter.

Table 3. Average results of the skin pigmentation evaluation on the forehead and the right cheek of volunteers.

\begin{tabular}{ccc}
\hline \multirow{2}{*}{ Day of Measurement } & (Number of Dark Spots in Dimensionless Units, $\mathbf{n}=\mathbf{3}$ for Each Skin Site; 24 Subjects) * \\
\cline { 2 - 3 } & Forehead & Right Cheek \\
\hline 0 & $0 \pm 2.8$ & $0 \pm 0.6$ \\
15 & $0 \pm 0.5$ & $0 \pm 0.7$ \\
30 & $0 \pm 0.3$ & $0 \pm 0.5$ \\
45 & $0 \pm 0.4$ & $0 \pm 0.8$ \\
\hline
\end{tabular}

${ }^{*}$ Results expressed as the mean \pm standard deviation of 3 separate determinations from each skin site in each subject.
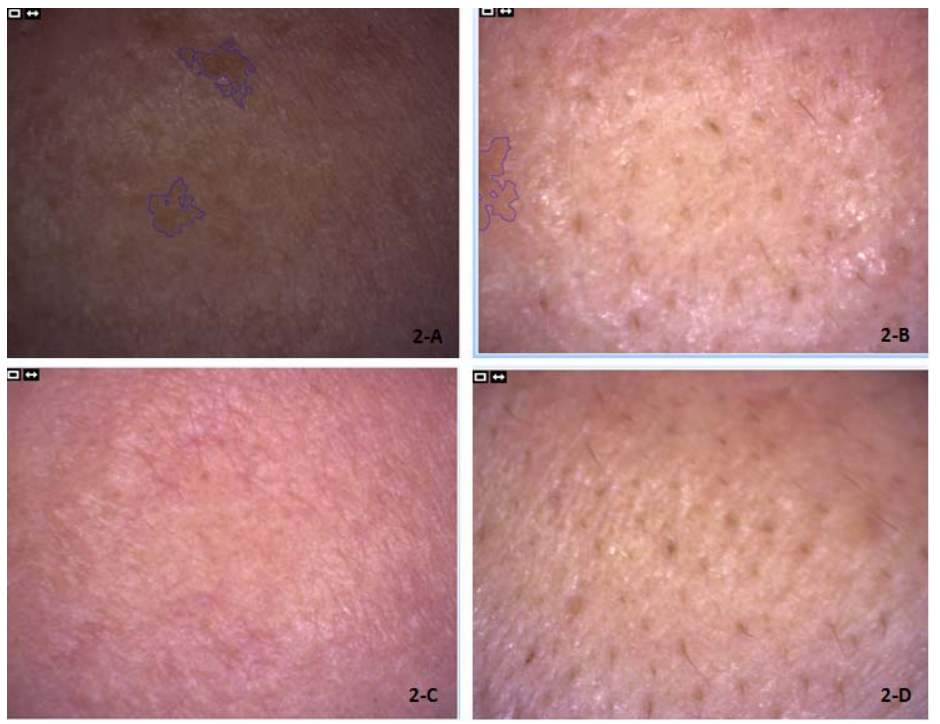

Figure 2. Graphic of typical results for the morning determination. (2-A): Spot on the right cheek and (2-B): Spot on the forehead, on day 0; (2-C): Spots on the right cheek and (2-D): Spot on the forehead on day 45 , both in volunteer 4 . Spots are demarcated in purple and calculated as number of dark spots in dimensionless units by the software. No spots found on figures (2-C) and (2-D).

\subsubsection{Wrinkle Evaluation}

Expression lines can be clinically classified as superficial when they disappear by skin stretching, or deep when there is no difference if the skin is stretched [17]. In the skin of the elderly the following occur: a decrease in the function of connective tissue, a degradation of elastic fibers, a lower amount of oxygen reaches the tissues, a higher loss of water occurs, and a hardening of collagen fibers takes place, resulting in the formation of wrinkles or expression lines $[15,17,21,25]$.

After 45 days of using the product, evaluation of both wrinkles and expression lines did not present any significant change, as shown in Table 4 and Figure 3. We obtained this same result even if we excluded volunteers with a low level of wrinkles at the beginning of the study, which is contrary to what is known about the antiaging properties of resveratrol. Limitations of interpreting this data are the limitations of the study itself, i.e., the small number of volunteers and the short duration of the study. For these specific parameters, probably a longer study (e.g., at least 5 months) could have detected the changes in wrinkles in volunteers better. 
Table 4. Average results of the wrinkles evaluation on the forehead, the right eye, and the right cheek of volunteers.

\begin{tabular}{cccc}
\hline \multirow{2}{*}{ Day of Measurement } & \multicolumn{2}{c}{ (Number of Wrinkles in Dimensionless Units, $\mathbf{n}=\mathbf{3}$ for Each Skin Site; 24 Subjects) } \\
\cline { 2 - 4 } & Forehead & Right Eye & Right Cheek \\
\hline 0 & $11.2 \pm 3.9$ & $15.2 \pm 2.4$ & $13.5 \pm 4.4$ \\
15 & $10.8 \pm 4.4$ & $16.3 \pm 1.9$ & $14.8 \pm 3.8$ \\
30 & $11.7 \pm 4.6$ & $16.0 \pm 2.5$ & $12.5 \pm 3.3$ \\
45 & $13.7 \pm 3.9$ & $16.2 \pm 2.7$ & $15.3 \pm 3.1$ \\
\hline
\end{tabular}

* Results expressed as the mean \pm standard deviation of 3 separate determinations from each skin site in each subject.
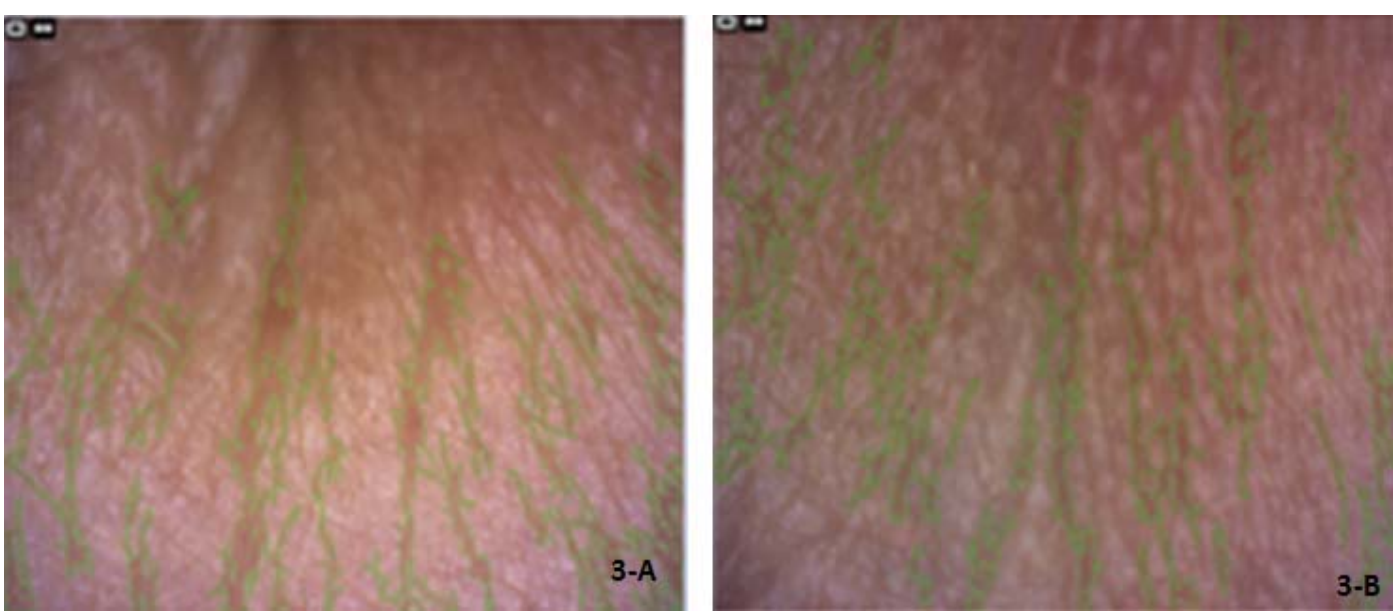

Figure 3. Graphic of typical results for the determination of expression lines, with demarcation in green lines. (3-A): Wrinkles in the outer corner of the right eye on days 0 and (3-B): Wrinkles in the outer corner of the right eye on day 45 , both in volunteer 17.

\subsubsection{Evaluation of Skin Barrier Function}

Xerosis cutis (dry skin) is a frequent skin change caused by the aging process [11]. It can be demoralizing for a person when there is a change in both the appearance and sensory aspect of their skin [11,25].

Hydration consists of keeping water inside the epidermis, and in this study, we used an indirect determination of skin hydration: the transepidermal water loss, which indicates the efficiency of the human skin as a water barrier $[9,16]$. During the study, it was observed that there was a discrete decrease in transepidermal water loss according to the area analyzed, as shown in Table 5, but no statistical significant result was found. A decrease in the average values can be seen for the forehead, chin and nose; but no difference was observed in the cheeks. This indicates that the product has no particular effect on this specific parameter.

Table 5. Average results of the evaluation of skin barrier function on the forehead, the right cheek, the left cheek, the chin, and the nose of volunteers.

\begin{tabular}{|c|c|c|c|c|c|}
\hline \multirow{2}{*}{ Day of Measurement } & \multicolumn{5}{|c|}{ Transepidermal Water Loss $\left(\mathrm{g} / \mathrm{m}^{2} \mathrm{~h}, \mathrm{n}=3\right.$ for Each Skin Site; 24 Subjects) * } \\
\hline & Forehead & Right Cheek & Left Cheek & Chin & Nose \\
\hline 0 & $20.1 \pm 7.7$ & $17.8 \pm 6.4$ & $18.4 \pm 7.7$ & $24.6 \pm 8.4$ & $24.0 \pm 7.6$ \\
\hline 15 & $22.8 \pm 7.1$ & $21.1 \pm 7.0$ & $21.0 \pm 5.5$ & $24.0 \pm 7.2$ & $27.7 \pm 6.6$ \\
\hline 30 & $20.0 \pm 8.6$ & $20.1 \pm 4.8$ & $19.3 \pm 5.5$ & $22.3 \pm 11.0$ & $23.0 \pm 8.6$ \\
\hline 45 & $16.1 \pm 8.7$ & $19.5 \pm 5.5$ & $18.4 \pm 6.3$ & $21.8 \pm 7.3$ & $22.4 \pm 6.0$ \\
\hline
\end{tabular}

${ }^{*}$ Results expressed as the mean \pm standard deviation of 3 separate determinations from each skin site in each subject. 


\subsubsection{Porphyrins Evaluation}

Lastly, we performed the porphyrins quantification, which is produced by P. acne bacteria, responsible for the biosynthesis of inflammatory mediators (Table 6 and Figure 4). The evaluation can be done with ultraviolet light because it emits reddish-orange fluorescence that makes both identification and quantification possible $[9,26]$.

Results for these parameters were conflicting when an increase in the quantities of porphyrins on the forehead, the right and left cheeks, and the nose was observed. This observation indicated that the cream was not capable of inhibiting the proliferation of the bacteria responsible for acne in those regions. However, when the chin region was evaluated, no significant change was detected, although porphyrins tended unexpectedly to increase in all the tested areas with the only exception of chin.
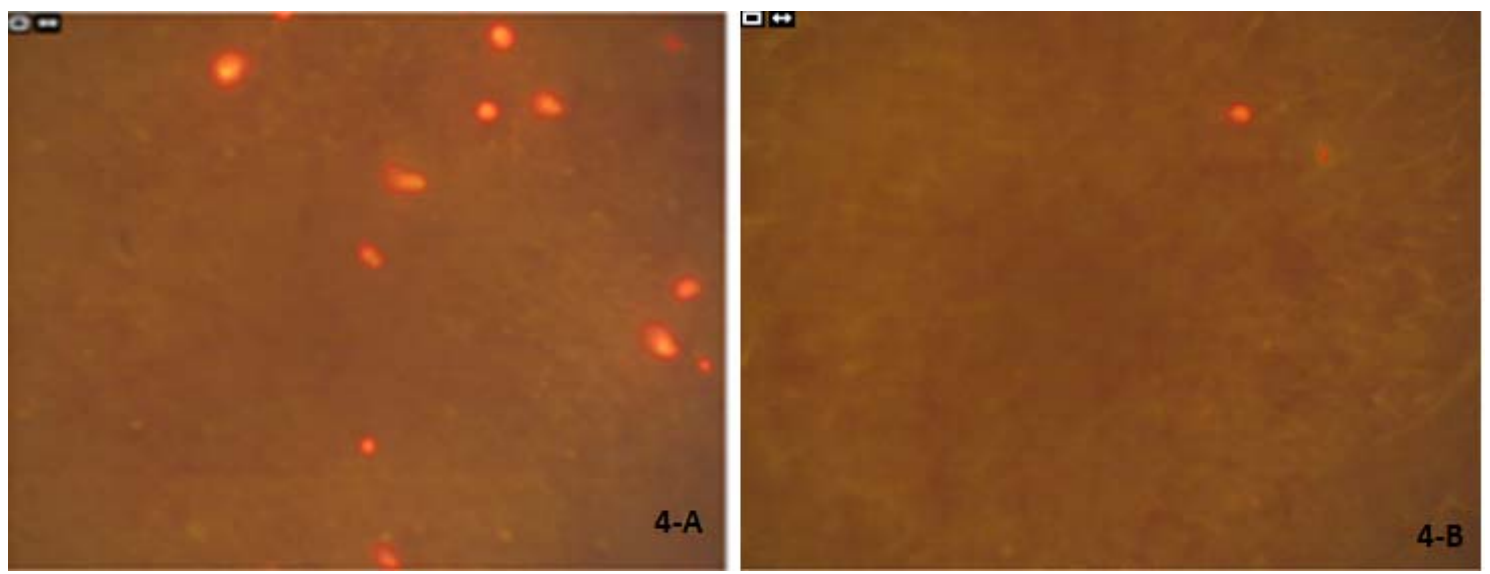

Figure 4. Graphic of typical results for the determination of porphyrins, visualized under UV light. (4-A): Porphyrins on the cheek on days 0 and (4-B): Porphyrins on the cheek on day 45, both in volunteer 23.

Table 6. Average results of the porphyrins evaluation on the forehead, the right cheek, the left cheek, the chin, and the nose area of volunteers.

\begin{tabular}{cccccc}
\hline \multirow{2}{*}{ Day of Measurement } & \multicolumn{5}{c}{ Porphyrin Value * (n = 3 for Each Skin Site; 24 Subjects) } \\
\cline { 2 - 6 } & Forehead & Right Cheek & Left Cheek & Nose & Chin \\
\hline 0 & $207.0 \pm 76.7$ & $203.0 \pm 87.0$ & $191.0 \pm 90.5$ & $222.5 \pm 49.7$ & $209.5 \pm 23.9$ \\
15 & $235.0 \pm 52.0$ & $219.5 \pm 66.3$ & $209.5 \pm 75.6$ & $239.0 \pm 19.4$ & $216.0 \pm 19.1$ \\
30 & $229.0 \pm 51.5$ & $212.5 \pm 64.6$ & $205.0 \pm 82.5$ & $238.5 \pm 50.2$ & $209.0 \pm 23.5$ \\
45 & $225.0 \pm 52.3$ & $211.0 \pm 84.1$ & $199.5 \pm 88.6$ & $231.0 \pm 19.9$ & $202.0 \pm 24.3$ \\
\hline
\end{tabular}

* Porphyrin Value is an estimate provided by the software based on the average quantity and size of facial spots with porphyrins. Results expressed as the mean \pm standard deviation of 3 separate determinations from each skin site in each subject.

\subsection{Questionnaire Evaluation}

At the end of the study, a questionnaire with short and direct questions was provided to all volunteers to both evaluate their perception about the cream and confirm the theoretical results. The results of the questionnaire are shown in Table 7.

Table 7. Questionnaire results about the perception of the formulation $(n=24)$.

\begin{tabular}{ccc}
\hline Parameters & $\mathbf{n}$ & $\%$ \\
\hline Opinion of Application Protocol & & \\
Comfortable & 20 & 83.3 \\
Uncomfortable & 1 & 4.2 \\
\hline
\end{tabular}


Table 7. Cont.

\begin{tabular}{|c|c|c|}
\hline Parameters & $\mathbf{n}$ & $\%$ \\
\hline Fast & 9 & 37.5 \\
\hline Slow & 0 & 0 \\
\hline \multicolumn{3}{|c|}{ Changes Noticed in Aspect or Appearance } \\
\hline Yes & 23 & 95.8 \\
\hline No & 1 & 4.2 \\
\hline \multicolumn{3}{|l|}{ Duration of Noticed Changes } \\
\hline 7 days & 13 & 54.2 \\
\hline 15 days & 9 & 37.5 \\
\hline 30 days & 1 & 4.2 \\
\hline 45 days & 0 & 0 \\
\hline No improvements & 1 & 4.2 \\
\hline \multicolumn{3}{|l|}{ Aspects Observed on Face } \\
\hline Decrease in expression lines & 6 & 25 \\
\hline Improvement in hydration & 20 & 83.3 \\
\hline Increase in natural brightness & 8 & 33.3 \\
\hline Improvement in general aspect & 12 & 50 \\
\hline Decrease in pores & 9 & 37.5 \\
\hline Decrease in oily skin & 11 & 45.8 \\
\hline Decrease in acne & 1 & 4.2 \\
\hline \multicolumn{3}{|l|}{ Pleased with Treatment } \\
\hline Less than satisfied & 3 & 12.5 \\
\hline Satisfied & 10 & 41.6 \\
\hline Highly satisfied & 10 & 41.6 \\
\hline Unsatisfied & 0 & 0 \\
\hline Highly unsatisfied & 1 & 4.2 \\
\hline \multicolumn{3}{|l|}{ Indication for Treatment } \\
\hline Yes & 24 & 100 \\
\hline No & 0 & 0 \\
\hline \multicolumn{3}{|c|}{ Use of other Cosmetic Products before the } \\
\hline \multicolumn{3}{|c|}{ Study } \\
\hline Yes & 12 & 50 \\
\hline No & 12 & 50 \\
\hline \multicolumn{3}{|c|}{$\begin{array}{l}\text { Schedule was Followed for Application of } \\
\text { Cream }\end{array}$} \\
\hline Yes & 13 & 58.3 \\
\hline No & 11 & 41.6 \\
\hline \multicolumn{3}{|l|}{ Number of Times Cream was not Used } \\
\hline 2 times & 7 & 29.2 \\
\hline 5 times & 2 & 8.3 \\
\hline 10 times & 0 & 0 \\
\hline More than 10 times & 2 & 8.3 \\
\hline
\end{tabular}

Based on the results as shown in Table 7, indicating volunteers' satisfaction during cosmetic use, $83.3 \%$ of volunteers were comfortable using the emulsion and $100 \%$ would recommend using the cosmetic use to someone else. Another aspect observed by volunteers was an increase in hydration of their skin and a decrease in the oiliness of their skin. In addition, $54 \%$ of volunteers noticed an improvement in their skin of any type after only seven applications of the product. Although no improvement in expression lines was observed, $25 \%$ of volunteers said they saw some improvement in this parameter. The effects were observed even with a high rate of non-adherence, which is a limiting of the study, together with the small sample size. Volunteers who forgot to use the cream on any day did not show differences, compared to the subjects which followed the protocol strictly, as only pore size on the forehead presented statistically significative differences between the baseline determination and the end of the study.

Finally, the results found in our study are conflicting with most reports from literature concerning resveratrol for cosmetic use. Traditional products with resveratrol have already been proved to minimally 
act against lipid peroxidation [8], as skin-lightening agent [8-11] and as photoprotective agent [7-10]. In this case, it seems that its incorporation into traditional topical dosage forms is more efficient than in liotropic liquid crystal emulsions. However, one must take into account the limitations of this trial (short time of follow-up and small population). A larger study could reflect better the potential of the formula for commercial anti-ageing products.

\section{Conclusions}

Liotropic liquid crystal emulsion containing resveratrol showed limited effects as an antiaging product, as the product affected only to a minor extent pore size on the forehead. Even so, $95.8 \%$ of the volunteers reported a high level of satisfaction with the product. Given this positive feedback, a larger study having a longer evaluation period is encouraged.

Supplementary Materials: The following are available online at www.mdpi.com/2079-9284/4/4/54/s1, Figure S1: Visual aspect of the liotropic liquid crystal emulsion containing resveratrol.

Acknowledgments: The authors thank both Faculdade Suprema and the NUPICS (Núcleo de Pesquisa e Inovação em Ciências da Saúde) for giving us the opportunity for conducting the study.

Author Contributions: Hudson Polonini, Nádia Rezende Barbosa Raposo, Marcos Antônio Fernandes Brandão and Anderson de Oliveira Ferreira conceived and designed the work, analyzed the data and revised all steps of the experiments critically, as well as revising the work critically for intellectual content and also given final approval of the version to be published; Rafaela Pereira de Oliveira, Laura Bonato Alves Oliveira and Camila Oliveira acquired and analyzed the data, drafted the work and gave final approval of the version to be published. All authors are accountable for all aspects of the work in ensuring that questions related to the accuracy or integrity of any part of the work are appropriately investigated and resolved.

Conflicts of Interest: The authors declare no conflict of interest.

\section{References}

1. Leal, L.B.; Sousa, G.D.; Seixas, K.B.; Souza, P.H.N.; Santana, D.P. Determination of the critical hydrophile-lipophile balance of licuri oil from Syagruscoronata: Application for topical emulsions and evaluation of its hydrating function. Bras. J. Pharm. Sci. 2013, 49, 167-173. [CrossRef]

2. Scotti, L.; Scotti, M.T.; Cardoso, C.; Pauletti, P.; Castro-Gamboa, I.; Bolzani, V.S.; Velasco, M.V.R.; Menezes, C.M.S.; Ferreira, E.I. Modelagem molecular aplicada ao desenvolvimento de moléculas com atividade antioxidante visando ao uso cosmético. Rev. Bras. Cienc. Farm. 2007, 43, 153-166. [CrossRef]

3. Fries, A.T.; Frasson, A.P.Z. Evaluation of antioxidant activity of antiage cosmetic. Rev. Contexto Saúde 2010, 10, 17-23. (In Portuguese)

4. Polonini, H.C.; Bastos, C.A.; Oliveira, M.A.; Silva, C.G.; Collins, C.H.; Brandão, M.A.; Raposo, N.R. In vitro drug release and ex vivo percutaneous absorption or resveratrol cream using HPLC with zirconized silica stationary phase. J. Chromatogr. B 2014, 1, 23-31. [CrossRef] [PubMed]

5. Baxter, R.A. Anti-aging properties of resveratrol: Review and report of a potent new antioxidant skin care formulation. J. Cosmet. Dermatol. 2008, 7, 2-7. [CrossRef] [PubMed]

6. Nenem, D.; Lemos-Senna, E. Preparação e caracterização de suspensões colidais de nanocarreadores lipídicos contendo resveratrol destinados à administração cutânea. Quím. Nova 2011, 34, 408-413. (In Portuguese) [CrossRef]

7. Guthrie, A.R.; Chow, H.-H.S.; Martinez, J.A. Effects of resveratrol on drug- and carcinogen-metabolizing enzymes, implications for cancer prevention. Pharma. Res. Per. 2017, 5, 1-6. [CrossRef] [PubMed]

8. Peretti, S.C.; Moreira, M.A.L.; Barreto, G.R.; Moraes, C.A.P. Resveratrol para cosméticos no clareamento da pele. InterfacEHS—Saúde, Meio Ambient. Sustentabilidade 2015, 10, 3-16. (In Portuguese)

9. Oliveira, C.S.; Silva, A.B.P.P.; Fagundes, L.L.; Raposo, N.R.B.; Ferreira, A.O.; Brandão, M.A.F.; Polonini, H.C. Development and preliminary cosmetic potencial evaluation of Melaleuca alternifolia Cheel (Myrtaceae) oil and resveratrol for oily skin. J. Dermatol. Res. Ther. 2016, 2, 1-6. [CrossRef]

10. Polonini, H.C.; Lima, L.L.; Gonçalves, K.M.; do Carmo, A.M.; Da Silva, A.D.; Raposo, N.R. Photoprotective activity of resveratrol analogues. Bioorg. Med. Chem. 2013, 21, 964-968. [CrossRef] [PubMed] 
11. Milan, A.L.K.; Milão, D.; Souto, A.A.; Corte, T.W.F. Estudo da hidratação da pele por emulsões cosméticas para xerose e sua estabilidade por reologia. Rev. Bras. Cienc. Farm. 2007, 43, 648-657. (In Portuguese) [CrossRef]

12. Park, J.; Boo, Y.C. Isolation of resveratrol from Vitis Viniferae Caulis and its potent inhibition of human tyrosinase. Evid. Based Complement. Alternat. Med. 2013, 2013, 1-11. [CrossRef] [PubMed]

13. Boock, K.P. Development and Evaluation of Physical Stability of Topical Emulsions Containing Liquid Crystals, Moisturizers and Cupuaçu (Theobromagrandiflorum) or (Theobromacacau) Butter. Master's Thesis, Faculdade de Ciências Farmacêuticas de Ribeiro Preto da Universidade de São Paulo, Ribeirão Preto, Brazil, October 2007.

14. Andrade, F.F. Development and Evaluation of Liquid Crystals Obtained in O/W Emulsions Based on Andiroba Oil and Phosphoric Ester. Master's Thesis, Faculdade de Ciências Farmacêuticas de Ribeiro Preto da Universidade de São Paulo, Ribeirão Preto, Brazil, April 2008.

15. Oriá, R.B.; Ferreira, F.V.A.; Santana, E.N.; Fernandes, M.R.; Brito, G.A.C. Estudo das alterações relacionadas com a idade na pele humana, utilizando métodos de histomorfometria e autofluorescência. An. Bras. Dermatol. 2003, 78, 425-434. (In Portuguese) [CrossRef]

16. Sociedade Brasileira de Dermatologia (SBD). Envelhecimento. Available online: http://www.sbd.org.br/ doenca/envelhecimento/ (accessed on 24 March 2017).

17. Souza, S.L.G.; Braganholo, L.P.; Ávila, A.C.M.; Ferreira, A.S. Recursos fisioterapêuticos utilizados no tratamento do envelhecimento facial. Rev. Fafibe Line 2007, 3, 1-7. (In Portuguese)

18. Chorilli, M.; Prestes, P.S.; Rigon, R.B.; Leonardi, G.R.; Chiavacci, L.A.; Scarpa, M.V. Desenvolvimento de sistemas líquido-cristalinos empregando silicone fluido de co-polímero glicol e poliéter funcional siloxano. Quím. Nova 2009, 32, 1036-1040. (In Portuguese) [CrossRef]

19. Silva, S.A.M.; Rigon, R.B.; Valarini, M.F.C.; Chorilli, M.; Leonardi, G.R. Análise da influência do agente umectante na estabilidade reológica e avaliação de cristais líquidos em formulações cosméticas. Rev. Bras. Farm. 2013, 94, 199-210. (In Portuguese)

20. Agência Nacional de Vigilância Sanitária (ANVISA). Guia de Controle de Qualidade de Produtos Cosméticos: Uma Abordagem Sobre os Ensaios Físicos e Químicos. Available online: http://www.anvisa.gov.br/ cosmeticos/material/guia_cosmetico.pdf (accessed on 20 March 2017). (In Portuguese)

21. Fagron. Informe técnico Base Fag Plus Cristal. Available online: https://www.yumpu.com/pt/document/ view /12643047 / produto-fagplustm-cristal-definicao-emulsao-livre-de-fagron (accessed on 5 December 2017). (In Portuguese)

22. Menoita, E.; Santos, V.; Santos, A.S. A pele na Pessoa Idosa. Available online: http:/ /journalofagingandinnovation. org/volume2-edicao1-janeiro2013/a-pele-na-pessoa-idosa/ (accessed on 19 February 2017). (In Portuguese)

23. Flament, F.; Francois, G.; Qiu, H.; Ye, C.; Hanaya, T.; Batisse, D.; Cointereau-Chardon, S.; Seixas, M.D.G.; Belo, S.E.D.; Bazin, R. Facial skin pores: A multiethnic study. Clin. Cosmet. Investig. Dermatol. 2015, 8, 85-93. [CrossRef] [PubMed]

24. Gonçalves, G.M.S.; Maia Campos, P.M.B.G. Ácido ascórbico e ascorbil fosfato de magnésio na prevenção do envelhecimento cutâneo. Infarma Ciênc. Farm. 2006, 18, 3-6.

25. Montagner, S.; Costa, A. Bases biomoleculares do fotoenvelhecimento. An. Bras. Dermatol. 2009, 84, $263-269$. [CrossRef] [PubMed]

26. Information and Operating Instruction for the Visiopor®PP34 with Software. Available online: http://www. courage-khazaka.de/index.php/en/all-downloads/downloads-en/file/414-visiopor-pp-34-n (accessed on 5 December 2017).

(C) 2017 by the authors. Licensee MDPI, Basel, Switzerland. This article is an open access article distributed under the terms and conditions of the Creative Commons Attribution (CC BY) license (http:/ / creativecommons.org/licenses/by/4.0/). 